\title{
Age-related improvements in a conceptual implicit memory test
}

\author{
SILVIA MECKLENBRÄUKER \\ University of Trier, Trier, Germany \\ ALMUT HUPBACH \\ University of Arizona, Tucson, Arizona \\ and \\ WERNER WIPPICH \\ University of Trier, Trier, Germany
}

\begin{abstract}
The present study investigated developmental improvements in category exemplar generation priming in children from kindergarten to older elementary school age. The strength of categorical links for atypical exemplars increases in this age range, whereas category knowledge for typical exemplars remains relatively stable. Therefore, in comparison with older children, younger children should show less categorical-relational encoding and, thus, less priming for atypical items but not for typical items. This expectation was confirmed in Experiment 1. In Experiment 2, picture versus word format at study dissociated implicit and explicit performance, indicating that the age-related increase in priming for atypical exemplars in Experiment 1 was not an artifact of explicit contamination. The findings suggest that developmental improvements in conceptual priming can be observed when the conceptual knowledge relevant for a given task improves over the age range tested.
\end{abstract}

Performance on explicit memory tests such as recall and recognition is known to improve substantially from early childhood to adolescence, and it depends upon factors such as the use of mnemonic strategies, elaboration of semantic memory, and metacognitive knowledge of one's memory abilities (for reviews, see Cowan, 1997; Schneider \& Bjorklund, 1998). In contrast, results from about 20 published studies indicate that priming on implicit memory tasks seems to exhibit little or no age-related changes from 3 to 14 years of age. This finding suggests that age-related memory improvements are not observed when mainly automatic uses of previous experiences are required. However, the most common task for assessing priming in children has been a perceptual task-picture identification (e.g., Drummey \& Newcombe, 1995; Hayes \& Hennessy, 1996; Parkin \& Streete, 1988; Perrig \& Perrig, 1993; Russo, Nichelli, Gibertoni, \& Cornia, 1995; Wippich, Mecklenbräuker, \& Brausch, 1989; for a developmental trend in this task, see Cycowicz, Friedman, Snodgrass, \& Rothstein, 2000).

Dissociations observed between different implicit tests have led researchers to classify memory tasks not only

We thank Susanne Kraft and Sabine Meter for their assistance with data collection. Furthermore, we thank Peter Graf, David Mitchell, and two anonymous reviewers for their valuable suggestions on earlier versions of this article. This research was supported by a grant from the Deutsche Forschungsgemeinschaft (German Research Foundation) to S.M. Correspondence concerning this article should be addressed to S. Mecklenbräuker, Department of Psychology, University of Trier, D-54286 Trier, Germany (e-mail: mecklen@uni-trier.de). according to the instructions given at test (implicit vs. explicit), but also according to the forms of information that they access or the types of processing that they require (see Roediger \& McDermott, 1993). Perceptual tasks are therefore distinguished from conceptual tasks. This distinction is emphasized by the transfer-appropriate processing (TAP) principle proposed by Roediger and colleagues (see Roediger \& McDermott, 1993). This principle states that tests of retention will benefit to the extent that the processing operations at test recapitulate those engaged during prior learning.

Conceptual tests emphasize the semantic relations between studied and tested items. They require conceptually driven processing by relying on the encoded meaning of concepts. In agreement with the TAP account, conceptual priming has typically been affected by conceptually driven manipulations at study such as levels of processing or elaboration of encoding (for a review, see Roediger \& McDermott, 1993; for exceptions, see Vaidya et al., 1997). Because older children have a more elaborated knowledge base and usually employ more refined semantic-elaborative encoding operations than younger children do (for reviews, see Cowan, 1997; Schneider \& Bjorklund, 1998), they should show more transfer on conceptual tasks under certain conditions.

Only a few studies on the development of conceptual priming have been published to date. Most have used a category exemplar generation task (Anooshian, 1997; Greenbaum \& Graf, 1989; Mecklenbräuker \& Wippich, 1995; Perez, Peynircioğlu, \& Blaxton, 1998; Perruchet, 
Frazier, \& Lautrey, 1995). After studying a list of items belonging to different superordinate categories (e.g., furniture), participants are presented with category names and are asked to produce the first exemplars of each category that come to mind. Some of the category names refer to instances presented at study (studied categories), whereas others do not (unstudied categories). Priming is demonstrated when more target exemplars are produced from the studied than from the unstudied categories.

According to Mulligan (1996; Mulligan, Guyer, \& Beland, 1999), category exemplar generation priming relies particularly on categorical-relational encoding processes. He suggested an item-specific-relational hy pothesis as a refinement or extension of the TAP view. As defined by Hunt and Einstein (1981), relational information refers to features shared by the to-be-retrieved items, whereas item-specific information refers to features unique to an item. Relational information is important for selecting effective retrieval strategies and for generating potential responses, whereas item-specific information provides discriminative or distinctive information during retrieval. Therefore, category exemplar generation priming relies particularly on relational encoding, whereas category-cued recall is sensitive to both item-specific and relational encoding. The relevant relational information is category-level information. Findings support the relational view of category exemplar generation priming. Manipulations that render the categorical structure of the study list more or less salient affect categoricalrelational encoding and, thus, priming. For instance, blocking studied exemplars by category under semantic encoding conditions increases priming (e.g., Mulligan et al., 1999; Rappold \& Hashtroudi, 1991). Generating category names for studied exemplars has the same effect, but only when the category name produced is the one given later at test (Cabeza, 1994).

At first glance, the results of the few developmental studies on category exemplar generation priming seem to indicate age invariance. However, most of the studies have problems, making such a conclusion premature. Priming relies on categorical-relational encoding that is probably affected by conceptual knowledge of taxonomic categories. The largest improvements in this knowledge occur from preschool to older elementary school age (for reviews, see Bjorklund, 1985, 1987; Chi \& Ceci, 1987). Therefore, a developmental increase in priming should be observed in this age range. However, only two studies (Mecklenbräuker \& Wippich, 1995; Perez et al., 1998) have examined priming over this age range.

Perez et al. (1998) found age-invariant priming in two experiments done with 4-, 8-, and 20-year-old participants. However, it cannot be excluded that the categorical structure of the study lists was least salient for the adults and most salient for the preschoolers. The study lists contained six targets from one category and two fillers for the 4-year-olds, and six targets from each of three different categories and eight fillers for the 20-yearolds. Thus, although items were randomly ordered, items from the same category must have been presented more often in adjacent positions for younger than for older participants.

In two experiments, Mecklenbräuker and Wippich (1995) obtained similar amounts of priming in 5- to 6year-old and 8- to 12-year-old children. In Experiment 1, however, priming scores were very low (5\%), though reliable. The failure to find a developmentalincrease in Experiment 2 might have been due to the selection of the study items. As in most adult and child studies, the items were moderately typical members of their categories (mean baseline scores of 17\%).

Perruchet et al. (1995) concluded from their results that category exemplar typicality may be an important variable. Second and fourth graders showed comparable amounts of priming when study items were typical members of their categories (Experiments 1 and 2). In contrast, an age-related increase was observed for atypical exemplars in Experiment 1. However, this finding could not be replicated in Experiment 2, only a small age range was tested, and the study was not designed to manipulate item typicality. Instead, items were a posteriori dichotomized according to their typicality.

Why might exemplar typicality be an important variable in developmental studies? A category exemplar generation task requires categ ory knowledge. Studies on the development of this knowledge have identified exemplar typicality as a very important variable (for reviews, see Bjorklund, 1985, 1987; Chi \& Ceci, 1987). Atypical exemplars (e.g., butterfly for animal) show a stronger agerelated increase in connection strength to the category name from preschool to elementary school age than do typical exemplars (e.g., horse for animal) (e.g., Bjorklund, Thompson, \& Ornstein, 1983; Caplan \& Barr, 1989; Rosch, 1973). For instance, the age-related improvement in category verification times is greater for atypical than for typical exemplars (Rosch, 1973).

Bjorklund (e.g., 1985, 1987; Schneider \& Bjorklund, 1998) and other researchers' (e.g., Chi \& Ceci, 1987) assumptions about the influence of knowledge development on explicit memory tasks rely on network models of semantic memory. Bjorklund (1985) proposed that associations among entries in semantic memory become more numerous and stronger with increasing age, resulting in the relatively automatic activation of these relations in memory tasks. For all age groups, categorical relationsthat is, connections to the category name as well as intermember links - are stronger for typical exemplars and, thus, more easily activated than categorical relations for atypical instances. This leads to better organization and recall for typical than for atypical exemplars (see, e.g., Bjorklund \& Thompson, 1983). Most important, this typicality effect should be more pronounced in young children, because categorical relations for atypical exemplars are much weaker in younger than in older children. In agreement with this prediction, it has been shown that younger children fairly consistently sort, classify, and cluster items categorically when typical members of cat- 
egories are used, but - unlike older children-not when atypical members are studied (cf. Chi \& Ceci, 1987).

Our assumptions concerning the influence of knowledge development on category exemplar generation priming were based on the earlier described relational view proposed by Mulligan (1996). According to this processoriented account of implicit memory, developmentalimprovements in category knowledge might influence implicit memory via the same mechanisms whereby they affect explicit memory. Specifically, enhanced category knowledge for atypical items favors the processing of categorical-relational information at study and, thus, leads to more possible retrieval routes to the primed items at test. One might argue, however, that developmental improvements in the category knowledge for atypical items should affect both the unprimed (baseline) and the primed items. To avoid problems associated with baseline differences (see, e.g., Parkin, 1993), the items in the present study were selected according to age-appropriate category production norms. Consequently, the atypical items were equally unlikely to be produced spontaneously in both age groups. This does not mean that they were incorporated into the category knowledge to the same extent in both age groups. Whereas older children might rarely produce atypical items because of the large number of more typical exemplars that come to mind, younger children might rarely produce them because their categorical links are weaker. Because category knowledge for typical items remains relatively stable from preschool to older elementary school age, the categorical structure of study lists containing more typical members of familiar categories should be salient even for preschoolers, and thus, no age-related improvements in priming were expected.

To test the hypothesis that there should be an age-related increase in priming only for atypical items, and not for typical items, typicality was varied in Experiment 1. Half of the participants in each age group studied lists containing typical members of familiar categories (e.g., shoe for clothing and bed for furniture), whereas the other half studied atypical exemplars of the same categories (e.g., hat for clothing and TV set for furniture). Agerelated differences in both the content and structure of taxonomic categories are greatly minimized by the time a child is approximately 9 or 10 years of age (e.g., Bjorklund et al., 1983). Therefore, 6-year-old kindergartners were compared with 9- to 11-year-old fourth graders. Experiment 2 was designed to exclude the possibility that a developmental increase in priming was an artifact of explicit contamination.

\section{EXPERIMENT 1}

Items were presented as colored line drawings. In a pilot study, preschoolers did not show reliable priming when only the naming of pictures was required at study. Therefore, the experimenter provided the category name after a child had named a picture. This category classifi- cation condition should render the categorical structure of the study list more salient and should lead to levels of priming that allow the detection of reliable age-related improvements. Although at study the names of the studied categories had already been presented together with the exemplars, the implicit test was conceptual because retrieval was guided by the semantic rather than the perceptual content of the category name. At test, children were presented with category names and were asked to produce the first exemplars of each category that came to mind.

The target items were carefully selected to meet the following four criteria. First, and most important, the targets were evaluated in terms of typicality by age-matesthat is, on the basis of age-appropriate norms for each age group. This means that they were equally typical and atypical for both age groups. This should prevent baseline differences between the two age groups and, thus, should reduce concerns about whether priming should be calculated in absolute or relative-to-baseline terms (e.g., Parkin, 1993). Second, when explicitly questioned about category membership in a pilot study, children included the atypical exemplars in the appropriate categories. Therefore, although category-exemplar associations were weak, they were nevertheless preexistent. Third, the aty pical exemplars did not differ from the typical ones in item familiarity. All atypical items were highly familiar to children (e.g., hat for clothing). Fourth, there were no obvious associative relations between exemplars of a category, because previous research suggests that younger children's organization of categorizable information is more associative than categorical (e.g., Bjorklund, 1985, 1987).

Following the implicit test, all children were given an explicit cued recall test with the category names of the studied categories serving as cues. We expected to find the usually reported age-related improvements and a typicality effect (Bjorklund \& Thompson, 1983). Results of the explicit test must be interpreted with caution because of possible carryover effects from the preceding implicit test. We tolerated this problem, however, because we were primarily interested in implicit memory performance.

\section{Method}

Participants and Design. Thirty-two 6-year-old kindergartners (mean age $=6$ years, 1 month; range $=5$ years, 6 months to 6 years, 6 months; 16 girls, 16 boys) were recruited from kindergartens in Trier, and thirty-two 10-year-old fourth graders (mean age $=9$ years, 9 months; range $=9$ years, 4 months to 10 years, 9 months; 16 girls, 16 boys) were recruited from elementary schools in Trier. Participants in the two experiments reported in this article were all volunteers who received small gifts at the end of the experiment. Written consent was obtained from all parents of children who participated in the study.

The experiment comprised a $2 \times 2 \times 2$ mixed factorial design for the implicit test. The between-subjects variables were age and item typicality. Half of the children in each age group were randomly allocated to the typical study lists; the other half received the atypical lists. Item type at test (studied vs. unstudied) was varied within subjects. 
Materials. For each age group and each degree of typicality, two lists of 16 targets were constructed. The 16 targets were four members of four familiar superordinate categories (e.g., furniture, clothing), with different categories represented on each of the two lists. In addition, each list included two practice items at the beginning and two fillers at the end. The children received one of the lists during the study phase; the other list served as a new list for the implicit memory test. Across participants, each list served as a study list and as a new list at test equally often.

Items were selected on the basis of German category production norms (Hasselhorn, Jaspers, \& Hernando, 1990; Hupbach \& Mecklenbräuker, 1998) and from a pilot study. Items that had been produced by more than $30 \%$ but less than $60 \%$ of the children of a given age group were classified as typical; items that had been produced by at least $5 \%$ and less than $12 \%$, as atypical. Additional pilot studies ensured that the targets were familiar and that the typical and the atypical targets did not differ in familiarity. Furthermore, there were no obvious associative relations between the targets from the same category (i.e., items such as shoe-sock were not used). Whereas the superordinate categories were identical for the two age groups, 3 of the 16 targets in each list were different. This could not be avoided, owing to age-related differences in category typicality of the items.

The items were presented as colored (red, yellow, green, or blue) line drawings. Most of them were selected from Snodgrass and Vanderwart (1980). Additional items were drawn in a similar manner. The drawings $(7 \times 10 \mathrm{~cm})$ were presented on white cards $(11 \times$ $15 \mathrm{~cm})$. The color was added to fill in the black outline of the drawing. All items could naturally appear in any of the four colors used. The targets were presented in a quasi-random order with no more than two targets from the same category or of the same color in adjacent positions.

Procedure. The children were tested individually in a quiet room at their kindergarten or school during a single session lasting about $25 \mathrm{~min}$. They were told that they were going to play a game in which they had to name some pictures. Subsequent memory testings were not mentioned, constituting incidental learning conditions. In the study phase, all children were asked to first name the pictures and their colors. They had $10 \mathrm{sec}$ for their answers. In case of an incorrect or missing response, the experimenter supplied the correct one. The experimenter provided the category name after a child had named the object and its color. For instance, she said "a hat is an article of clothing." The next picture was presented following an interval of $3 \mathrm{sec}$.

Following a 5-min distractor task, the children received the category exemplar generation task. To familiarize them with the procedure, they were given two practice trials with categories not used in the experiment. Subsequently, the four names of the studied categories and the four names of the unstudied categories were announced by the experimenter one at a time. The ordering was random, with the constraints that the first category be an unstudied one and that no more than two studied or two unstudied categories occur in sequence.

Children were read a category name together with a very typical exemplar. The older children were asked to produce eight exemplars for each category name, and the younger children to produce as many exemplars as possible. Children of both age groups were pushed to produce eight exemplars. This was important, because comparison of priming in different age groups is complicated if the numbers of items generated by the different groups are not equal. Eight exemplars were required to increase the likelihood that participants would produce instances other than the most common ones (Graf, Shimamura, \& Squire, 1985). The 6-year-old kindergartners in the experiments included in this article had no problem generating eight exemplars. In unpublished experimental work, however, several 4-year-olds were not able to fulfill this task requirement. The children were given a maximum of $90 \mathrm{sec}$ to respond to each category name. Pilot studies showed that this time limit gave children of both age groups enough time to generate eight exemplars.

Finally, a cued recall test was given to assess explicit memory performance. The names of the studied categories were read aloud to the children with instructions to recall any item they remembered from the study phase that belonged to the categories. The children were asked not to guess. Recall was terminated when a child said she/he could not remember any more items or when the maximum time limit of $90 \mathrm{sec}$ for a given category was reached.

\section{Results and Discussion}

The results from the explicit test will be reported first. They are presented and discussed only briefly, because of possible carryover effects. The significance level for all the results of this and the following experiment was set at $\alpha=.05$.

Cued recall. A response was scored as correct only if it matched exactly, was a synonym, or was the plural of the target. The mean proportions of correctly recalled target exemplars are depicted in Table 1. A 2 (age) $\times 2$ (item typicality) analysis of variance (ANOVA) yielded significant main effects of both variables and no interaction $(F<1)$. As expected, typical items $(M=.54)$ were recalled better than atypical ones $[M=.33, F(1,60)=$ $37.95]$, and the fourth graders $(M=.49)$ surpassed the kindergartners $\left[M=.38, F(1,60)=10.20, M S_{\mathrm{e}}=0.019\right]$.

An inspection of intrusions showed that almost all of them were members of the corresponding category, and many had been produced in the foregoing implicit test. Younger children produced more intrusions $(M=6.3)$ than did older children $[M=1.8, F(1,60)=26.57]$. Furthermore, children produced more intrusions when they had studied atypical exemplars $(M=4.8)$ as opposed to typical ones $\left[M=3.30, F(1,60)=3.3, M S_{\mathrm{e}}=11.86, p<\right.$ $.08]$. This was true for both age groups $(F<1$ for the interaction).

The results confirm expectations and previous findings. The observed typicality effect is consistent with the results of previous child (e.g., Bjorklund \& Thompson, 1983) and adult (e.g., Rappold \& Hashtroudi, 1991, Experiment 2) studies. It can be attributed to more efficient categorical-relational encoding processes for typical as opposed to atypical study lists.

Category exemplar generation. Priming effects were assessed by comparing the probability of producing instances from the study list and the probability of generating instances from the unstudied list, with the latter reflecting baseline performance. Accordingly, we recorded the proportion of targets produced to studied and to unstudied categories (for the mean scores, see Table 1).

A 2 (age) $\times 2$ (item typicality) ANOVA on baseline scores showed only the expected main effect of typicality $\left[F(1,60)=140.01, M S_{\mathrm{e}}=0.011\right]$. The main effect of age and the interaction were nonsignificant (both $F \mathrm{~s}<1$ ). As intended, targets chosen as typical had a much higher probability of being produced $(M=.37)$ than did atypical targets $(M=.06)$. Baseline performance for atypical targets was low, but for both age groups it was signifi- 
Table 1

Experiment 1: Mean Proportions and Standard Errors for Targets Generated or Recalled to Studied and Unstudied Categories and Mean Priming Scores as a Function of Age, Type of Test, and Item Typicality

\begin{tabular}{|c|c|c|c|c|c|c|c|c|c|c|c|c|}
\hline & \multicolumn{6}{|c|}{ Atypical } & \multicolumn{6}{|c|}{ Typical } \\
\hline & \multicolumn{2}{|c|}{ Studied } & \multicolumn{2}{|c|}{ Unstudied } & \multicolumn{2}{|c|}{ Priming } & \multicolumn{2}{|c|}{ Studied } & \multicolumn{2}{|c|}{ Unstudied } & \multicolumn{2}{|c|}{ Priming } \\
\hline & $M$ & $\overline{S E}$ & $M$ & $\overline{S E}$ & $M$ & $\overline{S E}$ & $M$ & $\overline{S E}$ & $M$ & $\overline{S E}$ & $M$ & $S E$ \\
\hline \multicolumn{13}{|l|}{ Implicit test } \\
\hline Kindergarten & .18 & .03 & .07 & .02 & .11 & .03 & .57 & .03 & .36 & .02 & .20 & .04 \\
\hline Grade 4 & .24 & .02 & .05 & .01 & .19 & .03 & .55 & .04 & .38 & .04 & .16 & .06 \\
\hline \multicolumn{13}{|l|}{ Explicit test } \\
\hline Kindergarten & .27 & .04 & & & & & .48 & .03 & & & & \\
\hline Grade 4 & .38 & .04 & & & & & .59 & .03 & & & & \\
\hline
\end{tabular}

cantly greater than zero [both $t \mathrm{~s}(15) \geq 3.29$ ]. It might be argued that baseline scores were at the floor. This cannot be avoided, however, when the research question requires the presentation of atypical items in a category exemplar generation task (cf. Murphy, McKone, \& Slee, 2003, Experiment 1a; Vaidya et al., 1997, Experiment 4A). There were no age-related differences in baseline performance $(F<1)$. Thus, an absolute measure of priming (studied minus unstudied) was appropriate for age comparisons (for the mean priming scores, see Table 1).

All priming scores proved to be reliable [all $t \mathrm{~s}(15) \geq$ 2.88]. We had the specific hypothesis that there should be an age-related increase in priming for atypical items, and that there should be no age-related difference for typical items. This hypothesis referred to two simple main effects tests rather than a single test of the interaction of age and item typicality (for this distinction, see Levin, 1985). In this case, planned contrasts including directional ones represented a statistically more powerful alternative to an omnibus ANOVA (see, e.g., Levin, $1985,1997)$. Because of large baseline differences between typical and atypical items, it might be problematic to analyze absolute priming scores for typical and atypical items together in a single analysis. Therefore, priming scores for typical and atypical items were analyzed separately. As expected, an age-related increase was observed only for atypical items $[t(30)=1.94$, one-tailed $]$, and not for typical items $[t(30)=-0.56]$.

The developmental invariance in priming of typical items is consistent with the results of previous studies that used medium-typical (Anooshian, 1997; Greenbaum \& Graf, 1989; Mecklenbräuker \& Wippich, 1995; Perez et al., 1998) to high-ty pical(Perruchet et al., 1995) items. However, studies on the influence of item typicality might obtain different results depending on how item typicality is manipulated-between or within subjects. In an unpublished experiment conducted in our laboratory, half of the items presented for each category were atypical exemplars; the other half were typical category members. A developmental increase in priming was observed not only for atypical exemplars but also for typical exemplars. Given the use of mixed lists, atypical items might influence the salience of categorical information for typical items or vice versa.
The important finding of Experiment 1 was the reliable age-related increase in priming of atypical exemplars. It corroborates a result obtained by Perruchet et al. (1995, Experiment 1). Moreover, it was replicated in a recently published experiment by Murphy et al. (2003, Experiment 1a) in which only atypical items were used.

It might be argued that the observed developmentalimprovements in priming were an artifact of explicit contamination. That is, older children, who in the present experiment showed better explicit memory performance, may be more likely to detect the study-test relation in the implicit test, and having noticed this, they may be more likely to employ explicit retrieval strategies and to do so more efficiently than younger children. This seems rather unlikely, however, because age dissociated priming and cued recall for typical items. If the older children had been more likely to use explicit retrieval strategies in the implicit test, they should also have shown higher priming of typical items than the younger children did.

We tested this explicit contamination possibility by adopting the logic developed by Rappold and Hashtroudi (1991). If participants followed the implicit test instructions of spontaneously producing exemplars, they should first have generated very typical exemplars. Therefore, the proportion of the first few (i.e., the first three) items produced at test that were from the study list should have been much smaller than the same proportion for the explicit test in which participants were explicitly asked to recall only items from the study list. Furthermore, if the observed age-related improvement in priming was due to an unwanted use of explicit retrieval strategies in the older children, this proportion produced at the implicit test should have shown an age-related increase.

A 2 (age) $\times 2$ (item typicality) $\times 2$ (type of test) ANOVA on this proportion (for the mean scores, see Table 2) showed as the most important results a significant age $\times$ test type interaction $[F(1,60)=24.13]$ and a marginally significant triple interaction $[F(1,60)=3.82$, $\left.M S_{\mathrm{e}}=0.015, p<.06\right]$. For both the typical and the atypical items, the proportion of the first three items produced at the implicit test that were from the study list did not show an age-related increase $[F<1$ for the atypical items and $F(1,60)=2.55$ for the typical items]. Furthermore, the explicit test surpassed the implicit test in all 
Table 2

Mean Proportions and Standard Errors of the First Three Items Produced at Test That Were on the Study List as a Function of Age, Type of Test, and Item Typicality (Experiment 1) or Stimulus Presentation Mode (Experiment 2)

\begin{tabular}{|c|c|c|c|c|c|c|c|c|}
\hline & \multicolumn{4}{|c|}{ Atypical } & \multicolumn{4}{|c|}{ Typical } \\
\hline & \multicolumn{2}{|c|}{ Implicit } & \multicolumn{2}{|c|}{ Explicit } & \multicolumn{2}{|c|}{ Implicit } & \multicolumn{2}{|c|}{ Explicit } \\
\hline & $M$ & $S E$ & $M$ & $S E$ & $M$ & $S E$ & $M$ & $S E$ \\
\hline \multicolumn{9}{|l|}{ Experiment 1} \\
\hline Kindergarten & .12 & .03 & .32 & .05 & .49 & .05 & .53 & .04 \\
\hline Grade 4 & .15 & .03 & .48 & .05 & .41 & .03 & .75 & .04 \\
\hline \multicolumn{9}{|l|}{ Experiment 2} \\
\hline \multicolumn{9}{|l|}{ Picture } \\
\hline Kindergarten & .11 & .02 & .30 & .02 & & & & \\
\hline Grade 4 & .10 & .02 & .47 & .03 & & & & \\
\hline \multicolumn{9}{|l|}{ Word } \\
\hline Kindergarten & .09 & .03 & .19 & .03 & & & & \\
\hline Grade 4 & .13 & .03 & .36 & .04 & & & & \\
\hline
\end{tabular}

but one condition: The kindergartners who had studied typical items responded similarly to implicit and explicit test instructions. The large number of intrusions that they produced in cued recall suggests that their explicit memory performance was probably "contaminated" by priming. There was a relatively high probability of spontaneously producing the typical targets in the cued recall test. In contrast, this probability was rather low for atypical targets, and thus, the number of intrusions was very high. Given the fairly rudimentary memory strategies generally used by preschoolers (for a review, see Schneider \& Bjorklund, 1998), such a contamination of cued recall by priming is not surprising.

The preceding analysis indicates that the observed age-related improvements in priming of atypical items were not an artifact of explicit contamination, but were real improvements in the unintentional use of memory. However, to provide additional evidence against an artifact objection, we conducted a further experiment. Experiment 2 was designed to meet the retrieval intentionality criterion of Schacter, Bowers, and Booker (1989). According to this criterion, explicit retrieval in implicit tests may be ruled out if there is an experimental variable that dissociates the implicit from the explicit memory test, provided that the same nominal cues are used in both tests, and that the tests vary only in their instructions. It is assumed that the differential effect of the variable can then be attributed to the differences in the unintentional and intentional retrieval processes that are used to perform the tests. Only atypical items were used in Experiment 2, because a developmental increase in priming was expected and observed only for those items in Experiment 1.

\section{EXPERIMENT 2}

Most variables have similar effects on an implicit and an explicit memory test when both tests are conceptual (for a review, see Roediger \& McDermott, 1993). One variable that may lead to dissociative effects is the symbolic presentation mode (pictures vs. words) of the study items. In explicit tests, pictures are usually remembered better than words, a finding called the picture superiority effect (Paivio, 1971, 1991). This effect is also observed in children (see, e.g., Pressley, 1977). Many accounts assume that it results from richer semantic encoding. If so, it should also be observed in conceptual priming. Surprisingly, only a few adult studies have addressed this question. In most studies, picture superiority has not been obtained in category-exemplar generation or in any other conceptual implicit test when the study tasks ensure semantic encoding of the presented material (e.g., McDermott \& Roediger, 1996; Weldon \& Coyote, 1996; Wippich, Melzer, \& Mecklenbräuker, 1998; for a discrepant finding, see Nicolas, 1995). However, when study conditions induce a more extensive conceptual analysis for one presentation mode, a superiority for this mode is found. For instance, picture superiority has been found when pictures have to be named and words have to be read (Mitchell \& Bruss, 2003; Vaidya \& Gabrieli, 2000).

The usual failure to find a picture superiority effect on conceptual priming indicates that conceptual processing plays a minor role in superior explicit memory performance for pictures, and that visual distinctiveness (e.g., Nelson, 1979; Weldon \& Coyote, 1996) is likely to be a more important factor. Distinctiveness refers to the relative uniqueness of the features of a stimulus or event, relative to other information in the context. Because pictures are generally more variable in their features than words are, their sensory codes are usually more distinct than those of words (Nelson, 1979). Distinctiveness is very important in intentional retrieval. For example, in category-cued recall, participants might generate many exemplars of the given category but must discriminate studied from nonstudied exemplars. In contrast, in category exemplar generation, they need only to spontaneously produce any category member that comes to mind, without discriminating between studied and nonstudied items. Thus, distinctiveness is not important and a picture superiority effect is usually not found.

The main aim of Experiment 2 was to replicate the age-related improvement in priming of atypical items 
under conditions that meet the retrieval intentionality criterion. This is important because the older children in Experiment 1 also showed better explicit memory performance than the younger ones. Therefore, it was possible that their advantage in priming was due to the more likely and more efficient use of intentional retrieval attempts in the implicit test. A picture superiority effect in the explicit test, but not in the matched implicit test, would suggest that children followed the test instructions- that is, that they used intentional retrieval processes in the explicit test and unintentional retrieval processes in the implicit test. In contrast, if the older children used intentional retrieval in the implicit test, they should show a picture superiority effect not only in the explicit but also in the implicit test.

The implicit and explicit tests were matched as closely as possible. Therefore, unstudied categories were presented in both tests. At study, the children - not the experimenterhad to classify the items into categories. This change should enable a generalization of findings to study conditions that render the categorical structure of study lists salient.

\section{Method}

Participants and Design. The participants were sixty-four 6 -year-old kindergarten (mean age $=5$ years, 10 months; range $=5$ years, 0 months to 6 years, 11 months; 35 girls, 29 boys) and 6410 year-old fourth graders (mean age $=10$ years, 4 months; range $=9$ years, 6 months to 11 years, 1 month; 30 girls, 34 boys). They were recruited from kindergartens and elementary schools in Trier and the surrounding areas.

The experiment comprised a $2 \times 2 \times 2 \times 2$ mixed factorial design. The between-subjects variables were age (kindergarten vs. elementary school), stimulus presentation mode at study (pictures vs. words), and type of memory test (implicit vs. explicit). In each age group, equal numbers of children (i.e., 16) were randomly allocated to the four experimental conditions resulting from the combination of presentation mode and type of test. Item type at test (studied vs. unstudied) was varied within subjects.

Materials and Procedure. With some exceptions, the materials were similar to those in Experiment 1. First, the study lists contained only atypical exemplars. Second, in the picture condition, the line drawings appeared in many different colors. Third, for half of the children, the items were presented verbally - that is, announced by the experimenter. The presentation orders for word and picture lists were matched.
In the picture condition, the experimenter presented a picture and named it at the same time. Unlike in Experiment 1, the children were not asked to name the pictures, because naming pictures leads to a more extensive conceptual analysis than does listening to words (see Vaidya \& Gabrieli, 2000). In the word condition, the words were announced by the experimenter. After the presentation of each picture or word, the children were asked to categorize the item. They had to choose among the four categories represented on their study list. Each category was illustrated by a colored line drawing of a very typical exemplar. For instance, clothing was represented by a sweater. The four pictures were fixed side by side on the wall or on a blackboard. Different orders were used across participants. The children were asked to name the category to which the item belonged. Although all the items were atypical category members, even the kindergartners had no problem in classifying the items into the appropriate categories. Incorrect answers rarely occurred. In these cases, the children were asked whether the item could also belong to one of the other categories. The second answers were always correct.

Following a 5-min distractor task, the children received implicit or explicit test instructions. The implicit instructions were identical to those of Experiment 1. In both tests, the children started with generating exemplars to two sample categories. Subsequently, the children in the explicit test condition were reminded of the study phase. For each category name, the children first had to indicate whether there had been items on the study list that belonged to the respective category. In case of a hit, they were asked to recall the items but not to guess. In case of a correct rejection, they were to spontaneously generate exemplars to the given category name. If the children rejected a category that actually had been presented, they were corrected. This was done to induce intentional retrieval attempts. False alarms were not corrected.

\section{Results and Discussion}

Absolute priming scores served as a measure of implicit performance. Because unstudied categories were also included in the explicit test, comparable scores were calculated for the explicit test. This means that the explicit memory scores were also corrected for baseline performance. A pattern of results similar to that described below was obtained when the implicit and the explicit tests were analyzed separately with absolute priming scores as the measure of implicit performance and the proportion of targets recalled from studied categories as the explicit memory score.

A 2 (age) $\times 2$ (stimulus presentation mode) $\times 2$ (type of test) ANOVA on baseline scores (for the mean scores, see Table 3) did not yield any significant effects [all

Table 3

Experiment 2: Mean Proportions and Standard Errors of Targets Generated or Recalled to Studied and Unstudied Categories and Mean Priming Scores as a Function of Age, Type of Test, and Stimulus Presentation Mode

\begin{tabular}{|c|c|c|c|c|c|c|c|c|c|c|c|c|}
\hline & \multicolumn{6}{|c|}{ Picture } & \multicolumn{6}{|c|}{ Word } \\
\hline & \multicolumn{2}{|c|}{ Studied } & \multicolumn{2}{|c|}{ Unstudied } & \multicolumn{2}{|c|}{ Priming } & \multicolumn{2}{|c|}{ Studied } & \multicolumn{2}{|c|}{ Unstudied } & \multicolumn{2}{|c|}{ Priming } \\
\hline & $M$ & $S E$ & $M$ & $S E$ & $M$ & $S E$ & $M$ & $S E$ & $M$ & $S E$ & $M$ & $S E$ \\
\hline \multicolumn{13}{|l|}{ Implicit test } \\
\hline Kindergarten & .16 & .02 & .04 & .01 & .12 & .03 & .13 & .02 & .05 & .02 & .09 & .03 \\
\hline Grade 4 & .24 & .02 & .08 & .01 & .16 & .02 & .22 & .02 & .06 & .02 & .16 & .02 \\
\hline \multicolumn{13}{|l|}{ Explicit test } \\
\hline Kindergarten & .26 & .02 & .06 & .01 & .20 & .02 & .21 & .03 & .05 & .02 & .16 & .03 \\
\hline Grade 4 & .48 & .02 & .06 & .01 & .42 & .02 & .36 & .03 & .07 & .02 & .29 & .03 \\
\hline
\end{tabular}


$\left.F_{\mathrm{S}}(1,120) \leq 2.23\right]$. Although they were low, the baseline scores were all significantly greater than zero [all $t \mathrm{~s}(15) \geq 3.05]$.

All absolute priming scores (for the mean scores, see Table 3 ) proved to be reliable [all $t \mathrm{~s}(15) \geq 3.03$ ]. A 2 (age) $\times 2$ (stimulus presentation mode) $\times 2$ (type of test) ANOVA showed significant main effects of age $[F(1,120)=44.65]$, presentation mode $[F(1,120)=$ $8.67]$, and type of test $\left[F(1,120)=61.07, M S_{\mathrm{e}}=0.010\right]$. Whereas the age $\times$ presentation mode interaction was nonsignificant $[F(1,120)=1.04]$, significant age $\times$ test type $[F(1,120)=13.13]$ and presentation mode $\times$ test type $\left[F(1,120)=4.63, M S_{\mathrm{e}}=0.010\right]$ interactions were obtained. Analyses of simple main effects showed that explicit test instructions led to better performance than did implicit instructions both in kindergartners $[M=.18$ vs. .10, $F(1,120)=8.78]$ and in fourth graders $(M=.35$ vs. . 16$)$, but this effect was more pronounced in the older children $\left[F(1,120)=65.42, M S_{\mathrm{e}}=0.010\right]$. More important, agerelated improvements were observed in both categorycued recall $[M=.35$ vs. .18, $F(1,120)=53.11]$ and category exemplar generation $[M=.16$ vs. $.10, F(1,120)=$ 4.68, $\left.M S_{\mathrm{e}}=0.010\right]$.

The remarkable similarity of implicit performance observed in Experiments 1 and 2 indicated that it did not matter whether category classification was done by the experimenter or by the participants. It was more important that study conditions emphasized category-level information. The age-related increase in memory performance was stronger in the explicit than in the implicit test. This was expected because explicit performance is affected not only by relational processing but also by item-specific processing, retrieval strategies, and metamemorial processes.

The presentation mode $\times$ test type interaction indicated a picture superiority effect in the explicit test $[M=$ .31 vs. $.21, F(1,120)=12.99, M S_{\mathrm{e}}=0.010$ ], but not in the implicit test $(M=.14$ vs. . $12, F<1)$. The triple interaction proved to be marginally significant $[F(1,120)=3.28$, $\left.M S_{\mathrm{e}}=0.010, p<.08\right]$. Separate analyses of the implicit and explicit test showed that this was due to the explicit test. A marginally significant age $\times$ presentation mode interaction $\left[F(1,60)=3.56, M S_{\mathrm{e}}=0.011, p<.07\right]$ indicated that only the older children showed a picture superiority effect $[F(1,60)=13.95$ for the older children, and $F(1,60)=1.14, M S_{\mathrm{e}}=0.011$, for the younger children] . However, the younger children showed a picture superiority effect by producing fewer intrusions for the picture $(M=1.2)$ than for the word lists $(M=10.0$ or 2.5 per category). This effect was not observed in the older children. Most of them did not produce any intrusions at all.

The important new finding was the age-related increase in priming under conditions that met the retrieval intentionality criterion. There was a picture superiority effect in the explicit test, but not in the matched implicit test. This finding provides further support for the assumption that visual distinctiveness or item-specific in- formation is an important factor for picture superiority in explicit memory performance (see, e.g., Weldon \& Coyote, 1996). If pictures had made categorical-relational information more salient, they should have been remembered better in both tests.

We have recently replicated the main findings from the present experiment - that is, a parallel effect of age and a dissociative effect of stimulus presentation mode-in an experiment in which the names of the superordinate categories were never mentioned in the study phase. Instead, study lists were organized by category, in order to enhance categorical-relational encoding processes. The observed dissociation provides compelling evidence against an artifact explanation. If the older children used intentional retrieval attempts in the implicit test, they should have shown a picture superiority effect in this test, because they showed better explicit memory performance for pictures than for words. This was clearly not the case. An analysis of the proportion of the first three items produced in the implicit and the explicit test that were from the study list also indicated that explicit contamination was unlikely. The pattern of results (for the mean proportions, see Table 2 ) was very similar to that obtained in Experiment 1.

\section{GENERAL DISCUSSION}

In the present study, we investigated the development of conceptual priming in childhood. In two experiments with a category exemplar generation task, a developmental improvement in priming from kindergarten to older elementary school age was observed when atypical members of familiar taxonomic categories served as study items. The effect was not very large, but it was reliable in both experiments and in an unreported replication of Experiment 2. Moreover, we have provided evidence that makes it unlikely that the observed developmental increase was an artifact due to the use of intentional retrieval attempts in the older children.

It is important to note that we expected developmental improvements only when the conceptual knowledge and the conceptual processes relevant for a given conceptual implicit test showed developmental improvements. For example, we did not expect - and did not obtain - age differences in priming of typical items. Murphy et al. (2003) made a similar point by proposing that implicit memory performance might improve with age when the underlying knowledge base develops with age. Their results confirmed that expectation. Kindergartners, third and fifth graders, and adults showed similar amounts of priming when the underlying knowledge base was stable. This was the case for perceptual priming (Experiment 2a) and for a conceptual priming task in which associative relations were important (Experiment 3a). Consistent with our findings, a developmental improvement in a category exemplar generation task was observed when atypical exemplars had been studied (Experiment 1a). 
Murphy et al. (2003) emphasized the role of the developing knowledge base, whereas we prefer to stress the role of both knowledge and cognitive processes, because what a child knows affects how the information in a cognitive task is processed (see, e.g., Bjorklund, 1987). Our main hypothesis of age-related improvements in priming of atypical exemplars was guided by theoretical considerations and empirical findings that underline the role of exemplar typicality in the development of category knowledge. With study lists of categorically related items, both explicit and implicit memory performance rely heavily on categorical-relational encoding processes (see, e.g., Mulligan, 1996; Mulligan et al., 1999) or-in terms of activation views - on the activation and reactivation of categorical relations in semantic memory (see e.g., Bower's [1996] reactivation theory of implicit memory). These processes are guided by category knowledge. The importance of this knowledge for explicit memory performance was shown by Lindberg (1980, Experiment 2): Third graders surpassed adults in organization in recall and free recall performance when using categories more familiar to children than to adults and vice versa for adults' categories. We would expect a similar result for category exemplar generation priming.

Although reliable age-related improvements in priming were observed in the present study, improvements in explicit memory performance were more pronounced. Because the implicit and the explicit tests differed mainly (Experiment 1) or even only (Experiment 2 ) in the test instructions, differences in the use of stored information seem to be responsible for this finding. Implicit tests rely mainly on the unintentional use of previous experiences. In contrast, explicit tests rely mostly on intentional and controlled processes. Because deliberate retrieval attempts require retrieval strategies and metamemory, larger age-related differences should usually be observed in conceptual explicit than in conceptual implicit memory tests. Age-related differences in encoding processes might also contribute to this finding. It can be assumed that the older children did a more extensive conceptual analysis of the study items. This more extensive item-specific processing did not influence category exemplar priming, but positively affected cued recall performance.

One might argue that there are two possible sources of age-related improvements in conceptual primingdifferences in implicit retrieval processes and differences in encoding - and that our focus is on differences in encoding. However, in examining age differences in priming and indeed more broadly in studying memory, one cannot view encoding and retrieval processes separately. Successful retrieval depends on the match between encoding and retrieval operations (TAP principle). If categoricalrelational encoding processes are more likely in older children than in younger ones, then a developmental increase in priming should be observed. And-an assumption still to be tested-if categorical-relational encoding is more likely in younger children than in older ones, the age effect should then be reversed.

\section{REFERENCES}

Anooshian, L. J. (1997). Distinctions between implicit and explicit memory: Significance for understanding cognitive development. International Journal of Behavioral Development, 21, 453-478.

BJoRKLUND, D. F. (1985). The role of conceptual knowledge in the development of organization in children's memory. In C. J. Brainerd \& M. Pressley (Eds.), Basic processes in memory development: Progress in cognitive development research (pp. 103-142). New York: SpringerVerlag.

BJorkLUND, D. F. (1987). How age changes in knowledge base contribute to the development of children's memory: An interpretive review. Developmental Review, 7, 93-130.

Bjorklund, D. F., \& Thompson, B. E. (1983). Category typicality effects in children's memory performance: Qualitative and quantitative differences in the processing of category information. Journal of Experimental Child Psychology, 35, 329-344.

Buorklund, D. F., Thompson, B. E., \& Ornstein, P. A. (1983). Developmental trends in children's typicality judgments. Behavior Research Methods \& Instrumentation, 15, 350-356.

Bower, G. H. (1996). Reactivating a reactivation theory of implicit memory. Consciousness \& Cognition, 5, 27-72.

Cabeza, R. (1994). A dissociation between two implicit conceptual tests supports the distinction between types of conceptual processing. Psychonomic Bulletin \& Review, 1, 505-508.

CAPlAN, L. J., \& BARR, R. A. (1989). On the relationship between category intensions and extensions in children. Journal of Experimental Child Psychology, 47, 413-429.

CHI, M. T. H., \& CECI, S. J. (1987). Content knowledge: Its role, representation, and restructuring in memory development. Advances in Child Development \& Behavior, 20,91-142.

CowAn, N. (ED.) (1997). The development of memory in childhood. Hove, U.K.: Psychology Press.

Cycowicz, Y. M., Friedman, D., Snodgrass, J. G., \& Rothstein, M. (2000). A developmental trajectory in implicit memory is revealed by picture fragment completion. Memory, 8, 19-35.

Drummey, A. B., \& Newcombe, N. (1995). Remembering versus knowing the past: Children's explicit and implicit memory for pictures. Journal of Experimental Child Psychology, 59, 549-565.

Graf, P., Shimamura, A. P., \& Squire, L. R. (1985). Priming across modalities and priming across category levels: Extending the domain of preserved function in amnesia. Journal of Experimental Psychology: Learning, Memory, \& Cognition, 11, 386-396.

Greenbaum, J. L., \& Graf, P. (1989). Preschool period development of implicit and explicit remembering. Bulletin of the Psychonomic Society, 27, 417-420.

Hasselhorn, M., Jaspers, A., \& Hernando, M.-D. (1990). Typizitätsnormen zu zehn Kategorien von der Vorschule bis zur vierten Grundschulklasse [Typicality norms for 10 categories from preschool to fourth grade]. Sprache \& Kognition, 9, 92-108.

Hayes, B. K., \& Hennessy, R. (1996). The nature and development of nonverbal implicit memory. Journal of Experimental Child Psychology, 63, 22-43.

Hunt, R. R. \& Einstein, G. O. (1981). Relational and item-specific information in memory. Journal of Verbal Learning \& Verbal Behavior, 20, 497-514.

Hupbach, A., \& MecklenbräUker, S. (1998). Typizitätsnormen zu neun Kategorien für Kindergartenkinder zweier Altersstufen [Typicality norms for nine categories for kindergarten children of two different age groups]. Sprache \& Kognition, 17, 41-50.

LeVIN, J. R. (1985). Some methodological and statistical "bugs" in research on children's learning. In M. Pressley \& C. J. Brainerd (Eds.), Cognitive learning and memory in children (pp. 205-233). New York: Springer-Verlag.

Levin, J. R. (1997). Overcoming feelings of powerlessness in "aging" researchers: A primer on statistical power in analysis of variance designs. Psychology \& Aging, 12, 84-106.

LINDBERG, M. A. (1980). Is knowledge base development a necessary and sufficient condition for memory development? Journal of Experimental Child Psychology, 30, 401-410.

McDermott, K. B., \& Roediger, H. L., III (1996). Exact and conceptual repetition dissociate conceptual memory tests: Problems for 
transfer appropriate processing theory. Canadian Journal of Experimental Psychology, 50, 57-71.

MecklenbräUKer, S., \& WiPPICH, W. (1995). Implizites Gedächtnis bei Kindern: Bleiben auch bei konzeptgesteuerten Aufgaben alterskorrelierte Differenzen aus? [Implicit memory in children: Are there age differences with conceptually driven tasks?] Zeitschrift für Entwicklungspsychologie und Pädagogische Psychologie, 27, 29-46.

Mitchell, D. B., \& Bruss, P. J. (2003). Age differences in implicit memory: Conceptual, perceptual, or methodological? Psychology \& Aging, 18, 807-822.

Mulligan, N. W. (1996). The effects of perceptual interference at encoding on implicit memory, explicit memory, and memory for source. Journal of Experimental Psychology: Learning, Memory, \& Cognition, 22, 1067-1087.

Mulligan, N. W., Guyer, P. S., \& Beland, A. (1999). The effects of levels-of-processing and organization on conceptual implicit memory in the category exemplar production test. Memory \& Cognition, 27, 633-647.

Murphy, K., McKone, E., \& Slee, J. (2003). Dissociations between implicit and explicit memory in children: The role of strategic processing and the knowledge base. Journal of Experimental Child Psychology, 84, 124-165.

Nelson, D. L. (1979). Remembering pictures and words: Appearance, significance, and name. In L. S. Cermak \& F. I. M. Craik (Eds.), Levels of processing in human memory (pp. 45-76). Hillsdale, NJ: Erlbaum.

NICOLAS, S. (1995). The picture-superiority effect in category-association tests. Psychological Research, 58, 218-224.

PAivio, A. (1971). Imagery and verbal processes. New York: Holt, Rinehart \& Winston.

PAivio, A. (1991). Dual coding theory: Retrospect and current status. Canadian Journal of Psychology, 45, 255-287.

PARKIN, A. J. (1993). Implicit memory across the lifespan. In P. Graf \& M. E. J. Masson (Eds.), Implicit memory: New directions in cognition, development, and neuropsychology (pp. 191-206). Hillsdale, NJ: Erlbaum.

Parkin, A. J., \& Streete, S. (1988). Implicit and explicit memory in young children and adults. British Journal of Psychology, 79, 361-369.

Perez, L. A., Peynircioł́lu, Z F., \& Blaxton, T. A. (1998). Developmental differences in implicit and explicit memory performance. Journal of Experimental Child Psychology, 70, 167-185.

Perrig, W. J., \& Perrig, P. (1993). Implizites Gedächtnis: Unwillkürlich, entwicklungsresistent und altersunabhängig? [Implicit memory: Nonarbitrary, developmentally resistant, and independent of age?] Zeitschrift für Entwicklungspsychologie und Pädagogische Psychologie, 25, 29-47.

Perruchet, P., Frazier, N., \& Lautrey, J. (1995). Conceptual implicit memory: A developmental study. Psychological Research, 57, 220228.

Pressley, M. (1977). Imagery and children's learning: Putting the picture in developmental perspective. Review of Educational Research, 47, 585-622.
RAPPOLD, V. A., \& HASHTROUdI, S. (1991). Does organization improve priming? Journal of Experimental Psychology: Learning, Memory, \& Cognition, 17, 103-114.

Roediger, H. L., III, \& McDermott, K. B. (1993). Implicit memory in normal human subjects. In H. Spinnler \& F. Boller (Eds.), Handbook of neuropsychology (Vol. 8, pp. 63-131). Amsterdam: Elsevier.

Rosch, E. (1973). On the internal structure of perceptual and semantic categories. In T. E. Moore (Ed.), Cognitive development and the acquisition of language (pp. 11-144). New York: Academic Press.

Russo, R., Nichelli, P., Gibertoni, M., \& Cornia, C. (1995). Developmental trends in implicit and explicit memory: A picture completion study. Journal of Experimental Child Psychology, 59, 566-578.

SChacter, D. L., Bowers, J., \& Booker, J. (1989). Intention, awareness, and implicit memory: The retrieval intentionality criterion. In S. Lewandowsky, J. C. Dunn, \& K. Kirsner (Eds.), Implicit memory (pp. 47-65). Hillsdale, NJ: Erlbaum.

Schneider, W., \& BJorklund, D. F. (1998). Memory. In W. Damon (Series Ed.) and D. Kuhn \& R. Siegler (Vol. Eds.), Handbook of child psychology: Vol. 2. Cognition, perception, and language (5th ed., pp. 467-521). New York: Wiley.

SNodgrass, J. G., \& VANDERWART, M. (1980). A standardized set of 260 pictures: Norms for name agreement, image agreement, familiarity, and visual complexity. Journal of Experimental Psychology: Human Learning \& Memory, 6, 174-215.

VAIDYA, C. J., \& GABRIELI, J. D. E. (2000). Picture superiority in conceptual memory: Dissociative effects of encoding and retrieval tasks. Memory \& Cognition, 28, 1165-1172.

Vaidya, C. J., Gabrieli, J. D. E., Keane, M. M., Monti, L. A., GutiérreZ-Rivas, H., \& Zarella, M. M. (1997). Evidence for multiple mechanisms of conceptual priming on implicit memory tests. Journal of Experimental Psychology: Learning, Memory, \& Cognition, 23, 1324-1343.

Weldon, M. S., \& Coyote, K. C. (1996). Failure to find the picture superiority effect in implicit conceptual memory tests. Journal of Experimental Psychology: Learning, Memory, \& Cognition, 22, 670686.

Wippich, W., MecklenbräUKer, S., \& BRAusch, A. (1989). Implizites und explizites Gedächtnis bei Kindern: Bleiben bei indirekten Behaltensprüfungen Altersunterschiede aus? [Implicit and explicit memory in children: Are age differences not apparent in indirect memory tests?] Zeitschrift für Entwicklungspsychologie und Pädagogische Psychologie, 21, 294-306.

WipPich, W., Melzer, A., \& MecklenbräUker, S. (1998). Picture or word superiority effects in implicit memory: Levels of processing, attention and retrieval constraints. Swiss Journal of Psychology, 57, 33-46.

(Manuscript received October 4, 1999; revision accepted for publication August 5, 2003.) 